Rick Moyer, a research physicist at the University of California, San Diego, believes it is unethical for institutions to continue to churn out new $\mathrm{PhDs}$ trained for academic research, most of whom will be hoping for a tenuretrack position, when such positions are like gold dust. Moyer argues that $\mathrm{PhD}$ training could perhaps include business studies to prepare physicists for jobs in industry.

\section{Worldwide problem}

In France too, where 2,200 physics PhDs were awarded last year, there is a need for training to reflect the reality that most $\mathrm{PhDs}$ have to find work in industry, says Marc Joucla, director of the Association Barnard Gregory. ABG is a non-profit group offering seminars to doctoral students from different disciplines to help them to acquire a wider professional perspective than academic research alone.

Helmut Krauth of the German Physical Society, an industrialist with a metals company, Vacuum Schmelze, says that German industry is in general happy with the quality of physicists with $\mathrm{PhD}$ and diploma education. Nevertheless, he says, "professors should encourage students to get work experience during the summer". Such training

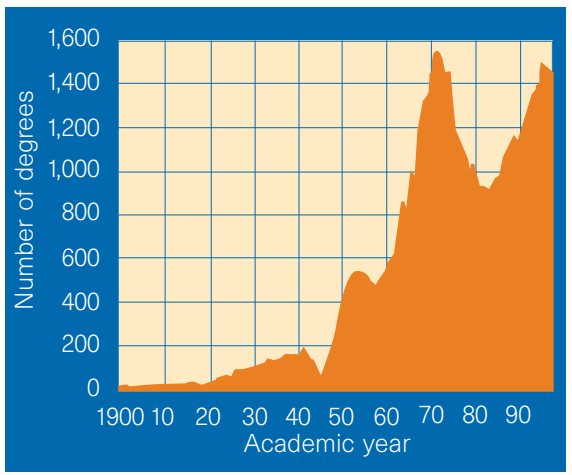

Education peaks: US physics PhDs rose in the 1980s, outstripping the number of faculty posts.

will set them up for work in industry, he says.

Moyer's argument for commercially based training had more force a few years ago than it does today, because companies used to be leaner and more focused. They did not want the expense of taking on $\mathrm{PhD}$ physicists who would need training for the job. In those stringent times, the much vaunted ability of the physicist to be flexible and apply skills to a variety of problems was not attractive when a company could employ someone with just the specialist skills they were looking for. Now that the US economy is booming, industry is once again being creative and expanding, and is attracted by the generalist skills of physicists. Software and telecommunications are particular growth areas.

Even though physicists are once again in demand, there is still a need to prepare $\mathrm{PhDs}$ for the reality of their future careers rather than the dream of success in the academic sphere. Native US physicists with PhDs now have to compete against physicists from elsewhere lured to the United States by companies offering better salaries than available in their own countries but lower than paid to their US counterparts, says Moyer.

\section{Industry beckons}

The consequence of a strong economy and the difficulty of getting postdoc positions that could lead to tenure-track jobs are reflected in the latest figures from the AIP. These show that the numbers accepting jobs in US industry have risen during the past decade. Ten years ago, just under half of all $\mathrm{PhDs}$ who took permanent jobs went to industry. Now the number is 70 per cent.

Not all of those in industry are happy. "Some are disappointed to be in the private sector because they thought they wanted to be physicists when they grew up," says

\title{
Exciting times at the interface with other disciplines
}

\section{Multidisciplinary research is of} increasing importance, according to the US National Science Foundation. "We are seeing excitement at the interface," says Jack Lightbody, executive officer of the foundation's physics division. Lightbody says there is work to be had for physicists in areas such as modelling social and biological systems, and in medical physics.

The UK Engineering and Physical Sciences Research Council (EPSRC) is thinking along similar lines. Its policy document published this month,

\section{Programme Landscape} 1999-2000, sees opportunities "for pioneering research across traditional boundaries". Helmut Krauth of the German Physical Society agrees: "There is a tendency to do more interdisciplinary research," he says.

The EPSRC, which funds university physics research (excluding particle physics and astronomy), plans a series of meetings to help physics cross interdisciplinary boundaries.
One example will focus on modelling and simulation for physicists, people in industry and other academics.

Interdisciplinary studies involving physics and environmental science and physics for healthcare will continue to be encouraged.

One new activity should help future job hunters interested in biophysics. The EPSRC plans to explore the opportunities in this area, believing that physics has much to offer the study of protein signalling networks, protein folding, biopolymers and colloids.

The physics and astronomy board of the US National Research Council also recognizes the value of links with biology in these days of shrinking physics budgets and blossoming biology funding (see Nature 397, 89; 1999). Explaining its current study into the future of physics, the board says: "To attract ambitious people in the future, it is necessary that physics concern itself with rapidly developing areas such as medicine and biology."
Several US universities have already spotted the intellectual value of promoting collaboration between physics and biology (see Nature 397, 3; 1999). Stanford University is investing in a new institute with 50 faculty members (including 10 new posts) that will draw together disciplines as disparate as applied physics and clinical medicine.

A survey conducted last year for the United Kingdom's higher education funding bodies confirmed the pervasiveness of interdisciplinary research in higher education. Threequarters of researchers are doing interdisciplinary work. The funding agencies commissioned the study as part of their consultation on the quality of the country's methods of assessing university research and apportioning funding. They wanted to know whether the research assessment method inhibits interdisciplinary research.

Preliminary findings are that most researchers are involved in both single discipline and interdisciplinary research. Of these, 23 per cent believe that the research assessment exercise strongly inhibits interdisciplinary research. Those who spend most of their time on interdisciplinary research have the greatest concern. Heads of academic departments for the most part thought that the assessment exercise had little effect on interdisciplinary research. The survey also found that research assessment panels are less interdisciplinary than the scientists whose work they are evaluating.

The full analyis, by Evaluation Associates, is due to be published soon. It is likely to extend the preliminary recommendations that more scientists with knowledge of interdisciplinary work should be included in research assessment panels. If physics is to continue reaching into new areas, implementation of these recommendations will be important.

The preliminary findings can be found at: http://wwww.evaluation.co.uk 